\title{
Link Budget Design for RF Line-of-Sight via Theoretical Propagation Prediction
}

\author{
Anwar H. Ibrahim 1, Mohammed F. Alsharekh², Mohammed S. Almanee1, \\ Abdulrahman S. Al-Turki', Muhammed Islam ${ }^{3}$ \\ ${ }^{1}$ Electrical Engineering Department, College of Engineering, Qassim University, Buraydah, Saudi Arabia \\ ${ }^{2}$ Electrical Engineering Department, Unaizah College of Engineering, Qassim University, Buraydah, Saudi Arabia \\ ${ }^{3}$ Electrical Engineering Department, Unaizah College of Engineering, Unayzah, Saudi Arabia \\ Email: dr.anwar@qec.edu.sa,m.alsharekh@qu.edu.sa,malmanee@qec.edu.sa, abdulrahman@qec.edu.sa, islam.eeng@gmail.com
}

How to cite this paper: Ibrahim, A.H., Alsharekh, M.F., Almanee, M.S., Al-Turki, A.S. and Islam, M. (2019) Link Budget Design for RF Line-of-Sight via Theoretical Propagation Prediction. Int. J. Communications, Network and System Sciences, 12 11-17.

https://doi.org/10.4236/ijcns.2019.121002

Received: December 22, 2018

Accepted: January 22, 2019

Published: January 25, 2019

Copyright $\odot 2019$ by author(s) and Scientific Research Publishing Inc. This work is licensed under the Creative Commons Attribution International License (CC BY 4.0).

http://creativecommons.org/licenses/by/4.0/

\begin{abstract}
Line-of-sight (LOS) link planning condition has been observed to have effects on the atmospheric factor which cause crucial signal loss. The main objective of the planning was to improve a set of a link using point to point condition to assist the performance in emerging its strategy for handling the fixed WLAN service. The purpose of this paper is to provide a quick description of various propagation loss mechanisms on Link Budget Tool (LBT). LBT is customized to create point to point link for local area network (LAN) through radio frequency range operating between $2.400 \mathrm{GHz}$ and $5.800 \mathrm{GHz}$. This software is able to define the effect of signal loss and expected performances according to the distances between link propagation conditions based on a number of system parameters.
\end{abstract}

\section{Keywords}

Path Loss (PL), Line of Sight (LOS), Microwave Link Budget (MLB),

Link Planning (LP)

\section{Introduction}

Daily have the great interests in utilizing a novel platform to provide best link prediction between point to point (PTP) due to the technology requirements [1] [2]. Radiofrequency link system used high-performance data, video transmission and management engine for advanced microwave through the wireless network [3]. This communication could allow the provision of personalized services in wireless connectivity as well as for sharing service engineering. Most of the industrial created a number of new possibilities for highly flexible link perfor- 
mance and efficient wireless communications for automation solutions [4].

Among wireless communication architecture, wireless link propagation is the most concerning process to have a success sharing purposes [5] [6]. The environment of radio applications is changing according to environmental factors [7]. Possible resources to the link consideration are based on a better understanding of the environmental factors affecting the link performance of the reliable transmission medium of the radio channel and it is important [8].

The best way of Radio Transmission which takes place under situations whereby a clear line of sight should exist between receiver and transmitter [9] [10]. This condition confirms the strongest conceivable signal with marginal attenuation according to environmental factors with no obstacles between the two sites.

To design an acceptable operational link with high quality at the lowest possible cost we must specify the requirements of the system performance, and then it is necessary to compute the power and bandwidth.

\section{Link Budget Plannıng Objectıves}

This planning presents the findings of a link budget and applied into the prospective future request for the range in frequency bands, which was presented for fixed links via point to point connection. This potential method carried out the fixed links in LAN applications, such as short range link among devices or satellite links. This planning elaborates the progress of a number of situations for local area network (LAN) service development and evaluating the situation of environmental impairment for spectrum allocation under each condition. The objectives of this planning are to attempt the link capacity quantify of certain frequency bands for fixed links where the future demand is heading to and other services were considered to be particularly high demand with fewer losses.

\section{Maintaining the Integrity of the Specifications}

There are three most important issues to be taken into consideration as far as propagation losses attention. Free space loss (FSL) in the line of sight condition is the principal factor in the loss of the signal strength and power spectral density (PSD). These losses referred to spreading signal through space. In addition, a key factor must be reserved and all the required calculations must be designed in a proper way as shown in the link power budget for any wireless communication.

Equation (1) expressed the Free Space Path Loss in decibels using a generic frequency $(f)$, versus distance $(D)[11]$ :

$$
\text { FSPL }=32.45+20 * \log (D)+20 * \log (F)
$$

where Free Space Path Loss (FSPL) is considered and calculated in dB in distance per kilometers for the given frequency in $\mathrm{GHz}$. and scenario

\section{Measuring Transmission Losses}

The purposes of the Link Budget Tools used excel software to determine the 
propagation impairments and it is a prediction for signal strength and surface roughness based on factor values found in the selected condition. The first step in this software was measured the ideal case to obtain the stream of the signal between point $A$ and point $B$ as shown in Figure 1. After adjusting the link performance, the gage of the signal starts to transmit from points $A$ and end at point $\mathrm{B}$ of the link, with different values of propagation impairments were calculated in the chart as shown in Figure 1.

The link budget software developed in this work is designed under the Excel platform; it is organized based in Figure 1 and Figure 2 to calculate the path loss. Furthermore, it has a list of options that comprehends all the different calculations that adequate the target performance of the link budget as system settings with a set of parameters that characterize [12], based on the distance between point $\mathrm{A}$ and Point $\mathrm{B}$.

Table 1 shows the major losses in point to point communication, however, the losses in the received signal perhaps have their basis of the signal in its propagation from the transmitter to the receiver. Table 1 intended to provide a clear understanding of the major propagation impairments, as well as their origin and cat gory. A part of these losses clarified to determine and validate the values attained for the calculations for link budget calculation.

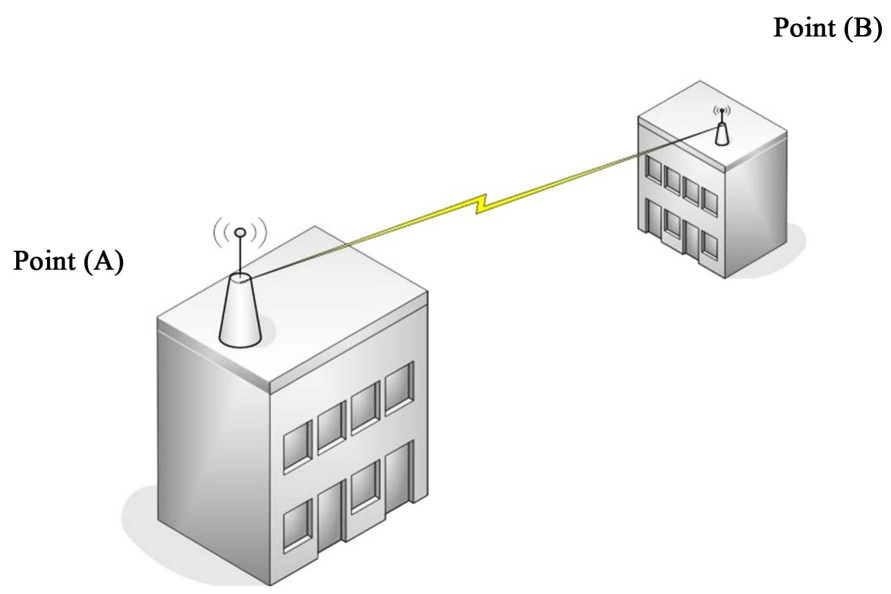

Figure 1. Point to point link condition.

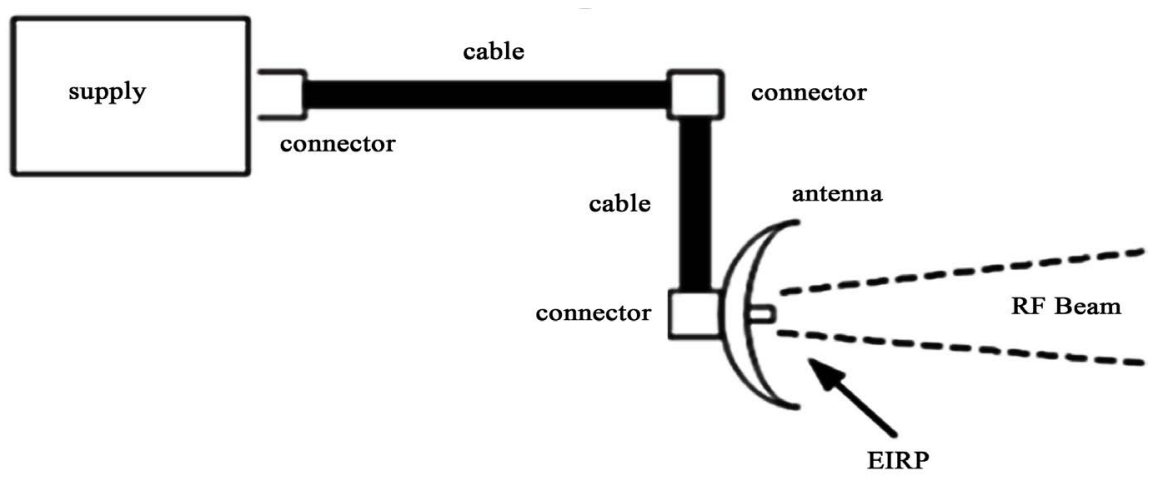

Figure 2. Equivalent isotropically radiated power. 
Table 1. Major losses in point to point communication.

\begin{tabular}{cccc}
\hline \multicolumn{3}{c}{ External Losses } & Internal Losses \\
\hline Free Space Losses & \multicolumn{2}{c}{ Impairment Path Losses } & Equipment Losses \\
\hline Signal Attenuation & Climate & Terrain Profile & Choosing Best Equipment \\
\hline $\begin{array}{c}\text { Antenna Pointing, Height } \\
\text { of the Pool, Fade Margin, } \\
\begin{array}{c}\text { Depolarization, } \\
\text { Receive Signal Strength }\end{array}\end{array}$ & $\begin{array}{c}\text { Temperature, } \\
\text { Humidity, } \\
\text { Channel Noise }\end{array}$ & $\begin{array}{c}\text { Mountains, Trees, } \\
\text { Buildings, } \\
\text { Antenna Height }\end{array}$ & $\begin{array}{c}\text { Connector Loss, Antenna } \\
\text { Gain, Feeder Loss, } \\
\text { Receiver Threshold, } \\
\text { Power of the antenna, } \\
\text { Atmospheric Absorption }\end{array}$ \\
\hline
\end{tabular}

\section{Link Budget Calculation Performance Prediction}

In any wireless transmission, there are continuously losses occurring from various sources during the transmission. Several losses may exist constant according to the device specifications; others are dependent on the nature of data and the environmental conditions, especially with rain.

When planning a communication for long distance to a remote two points, one of the most concerns is the successful link requirement. One considers is the information capacity and rate of error to calculate the signal strength required to not only reach the receiver, but to also reach with some level of high power or margin of loss, considering for the unexpected propagation impairments. Once the transmitter activates with the power capacity consists of the system gains and internal losses to determine the level of actual predicted power at the receiver. In order to ensure a consistent link between the transmitter and the receiver, the level of power delivered to the receiver should be obtained a minimum level of performance that required.

For the selected scenario, the basic transmission loss considered to be constant as shown in Tables 2-4 of a radio link between the free-space condition for the transmitter, receiver and general reference respectively. Table 5 shows the reference values for the channel specification in ideal cases. The related losses in the first step in the design for FSL are to define the losses in clear LOS conditions and these losses are remaining constant in all cases.

Based on a set of parameters that characterize the link, for this case was configured to work on $5.800 \mathrm{GHz}$ and $2.400 \mathrm{GHz}$ frequency. Among these constraints, there are already presets parameters such as synchronizes of the points and the location of the points [8] to estimate the exact signal strength in the given distance between them.

The losses in Tables 2-5 were considered as the input of the link in the ideal case. Link budget calculation is also introduced accurately the entire sources of each factor and allow the exact conception of all the presented analysis as shown in Figure 3.

\section{Conclusion}

This paper presented a feasibility study of purely theoretical prediction of the 


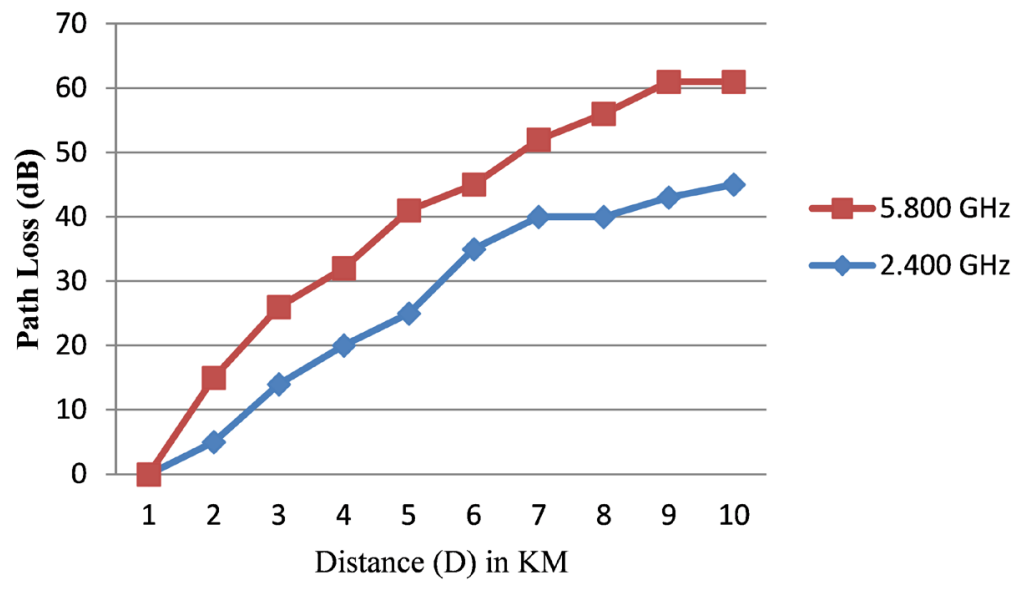

Figure 3. Free space path loss.

Table 2. Performance prediction.

\begin{tabular}{ll}
\hline Availability & $100 \%$ \\
Outage Time & 0.00 \\
Availability & $100 \%$ \\
Outage Time & 0.00 \\
Availability & $100 \%$ \\
Outage Time & 0.00 \\
\hline
\end{tabular}

Table 3. Constant values for the transmitter specification.

\begin{tabular}{cc}
\hline Transmitter & Point A \\
\hline Transmitter Power (Power out) & $23.00 \mathrm{dBm}$ \\
Transmission Line (Tx) & $1.5 \mathrm{~m}$ \\
Transmit Feeder Loss (TFL) & $1.00 \mathrm{~dB}$ \\
Tx Antenna Gain (TAG) & $32.00 \mathrm{~dB}$ \\
Connector Loss (CL) & $3.00 \mathrm{~dB}$ \\
\hline
\end{tabular}

Table 4. Constant values for the transmitter specification.

\begin{tabular}{cc}
\hline Receiver & Point B \\
\hline Connector Loss (CL) & $3.00 \mathrm{~dB}$ \\
Rx Antenna Gain (RAG) & $32.00 \mathrm{~dB}$ \\
Receive Feeder Loss (RFL) & $1.00 \mathrm{~dB}$ \\
Transmission Line (Rx) & $1.00 \mathrm{~m}$ \\
Receiver Threshold & $91.00 \mathrm{dBm}\left(\mathrm{BER} 10^{-3}\right)$ \\
RSL & $-34.00 \mathrm{~dB}\left(\mathrm{BER} 10^{-6}\right)$ \\
Fade Margin & $55.00 \mathrm{~dB}\left(\mathrm{BER} 10^{-6}\right)$ \\
\hline
\end{tabular}


Table 5. Reference values for the channel specification.

\begin{tabular}{cc}
\hline Reference & Terrain \\
\hline Average & 0.98 \\
Mountainous & 0.115 \\
Dry & 0.96 \\
Humid & 0.498 \\
\hline
\end{tabular}

received signal strengths in limited condition with selected losses, while this work is considered as an initial stage for a further proceeding to advance system. For well-developed a theoretical prediction, it could evaluate the actual breakpoint counters and predicted signal strength efficiency. Therefore, the importance of this link budget software used the theoretical method to enhance the system. A systematic link budget design is adopted for propagation prediction. The software is used to investigate the link configuration based on the received signal strength in a given distance. The purpose of this paper is to predict the signal strength and losses between two points based on theoretical approaches utilizing the various aspects and parameters. The main objective of this software is to predict the effect of different frequencies in various factors to obtain a lower loss, and the desired power to transfer certain information designed to carry data via the link budget. The theoretical method has shown that the overall path loss was mixed with propagation impairments at the optimum frequency range between $5.800 \mathrm{GHz}$ and $2.400 \mathrm{GHz}$.

\section{Conflicts of Interest}

The authors declare no conflicts of interest regarding the publication of this paper.

\section{References}

[1] Jabbar, S., Habib, M.A., Minhas, A.A., Ahmad, M., Ashraf, R., Khalid, S. and Han, K. (2018) Analysis of Factors Affecting Energy Aware Routing in Wireless Sensor Network. Wireless Communications and Mobile Computing, 2018, Article ID: 9087269.

[2] Toffel, M.W. (2004) Environmental Implications of Wireless Technologies: News Delivery and Business Meetings. Environmental Science \& Technology, 38, 2961-2970. https://doi.org/10.1021/es0350350

[3] Saeed, N., Celik, A. and Al-Naffouri, T.Y. (2018) Underwater Optical Wireless Communications, Networking, and Localization: A Survey. arXiv:1803.02442v1

[4] Javier Ferrer Coll. (2014) Channel Characterization and Wireless Communication Performance in Industrial Environments. Ph.D. Thesis, KTH University, Stockholm.

[5] Sandeep, D.N. and Kumar, V. (2017) Review on Clustering, Coverage, and Connectivity in Underwater Wireless Sensor Networks: A Communication Techniques Perspective. IEEE Access, 5, 11176-11199.

https://doi.org/10.1109/ACCESS.2017.2713640 
[6] Hoomod, H.K., Al-Mejibli, I. and Jabboory, A.I. (2018) Analyzing Study of Path Loss Propagation Models in Wireless Communications at $0.8 \mathrm{GHz}$. Journal of Physic, 1003, 1-7.

[7] Nadir, Z., Bait-Suwailam, M. and Idrees, M. (2016) Pathloss Measurements and Prediction Using Statistical Models. 20167 th International Conference on Mechanical, Industrial, and Manufacturing Technologies (MIMT 2016), MATEC Web of Conferences, Vol. 54, Cape Town, 1-3 February 2016, 1-4.

[8] Atayero, A.A., Luka, M.K. and Alatishe, A.A. (2011) Satellite Link Design: A Tutorial. International Journal of Electrical \& Computer Sciences IJECS-IJENS, 11, $1-7$.

[9] Mekid, S., Wu, D., Hussain, R. and Youcef-Toumi, K. (2017) Channel Modeling and Testing of Wireless Transmission for the Underground In-Pipe Leak and Material Loss Detection. International Journal of Distributed Sensor Networks, 13, 1-16. https://doi.org/10.1177/1550147717744715

[10] Aegis Systems Limited (2011) Frequency Band Review for Fixed Wireless Service. Final Report.

https://www.ofcom.org.uk/_data/assets/pdf_file/0022/51286/exe-summary.pdf

[11] Curran, S.J. (2018) Modeling the Use of an Airborne Platform for Cellular Communications Following Disruptions. Ph.D. Dissertation, Embry-Riddle Aeronautical University, Daytona Beach.

[12] Iskander, M. and Yun, Z. (2002) Propagation Prediction Models for Wireless Communication Systems. IEEE T Microwave Theory, 50, 662-673. 